$\begin{gathered}\text { EPiC Series in Education Science } \\ \text { Volume 1, 2017, Pages 54-61 }\end{gathered}$
$\begin{gathered}\text { AUBEA 2017: Australasian Universities Build- } \\ \text { ing Education Association Conference 2017 }\end{gathered}$

\title{
Early Contractor Involvement (ECI) in Event Planning and Management
}

\author{
C. Penn, K. L. Farnes", and F. Rahmani \\ School of Property, Construction and Project Management, \\ RMIT University, Melbourne. \\ chloe.penn@rmit.edu.au, kenneth.farnesermit.edu.au, \\ farshid.rahmaniermit.edu.au
}

\begin{abstract}
Large and mega-events employ traditional procurement approaches, adopting an adversarial stance with contractors/suppliers. These events are often beset with problems with the contractors/suppliers. This study investigates whether early contractor involvement (ECI) is being applied to the procurement processes within the event planning and management industry and to explore the potential benefits and challenges of the application of ECI within that industry. ECI attempts to exploit the contractor/supplier's specialist knowledge and expertise to the benefit the project planning and design process to provide mutual benefits and minimise the drawbacks associated with an adversarial contract. This paper argues that an event is a particular type of project and discusses the potential benefits of ECI to the event planning and management industry. A literature review approach was used to explore the construction and infrastructure industries and the event planning and management industry to determine whether ECI is being utilized to any meaningful degree. Overall the study findings indicate that by adopting ECI the event planning and management industry could expect similar benefits to those observed in the construction and infrastructure industries.
\end{abstract}

\section{Introduction}

\subsection{Is an event a project?}

A project is defined by the project management institute as “.... temporary endeavor undertaken to create a unique product, service, or result ... has a definite beginning and end" (PMI, 2013, p 3). The project management institute describes a typical project management lifecycle as having the five stages of: initiating, planning, execution, monitoring and control, and closing (PMI, 2013).

\footnotetext{
${ }^{*}$ Contact author for enquiries
} 
Projects come in a large variety of activities from construction, information technology, medical, business change, and events to name a few. Events are a particular type of project that includes conferences, exhibitions, festivals, special events, civic events, sports events and the like. Event management is the application of project management processes to development and execution of the event. The event management industry describes an event's lifecycle in the Event Management Book of Knowledge (EMBOK) in a similar manner to the project management institute's description of a project and although their stages or phases are named differently they correspond to the project management model, this similarity is not surprising as one of the key references used in the development of the EMBOK was the 2000 edition of PMBOK (Silvers, 2009).

An event is a form of a project and like construction, infrastructure and ICT projects they are categorized by their size. Müller (2015b) notes that terms like mega or giga-events are a recent phenomenon whereas previously they were described as large events.

For instance, Olympic Games as one of the leading international sporting events can be defined as a mega event since millions of people from cross the world attend the games and copious stakeholders are involved in the event. Figure 1 demonstrates the complexity of the various stakeholders' involvement in a typical Olympic Games event held every 4 years.

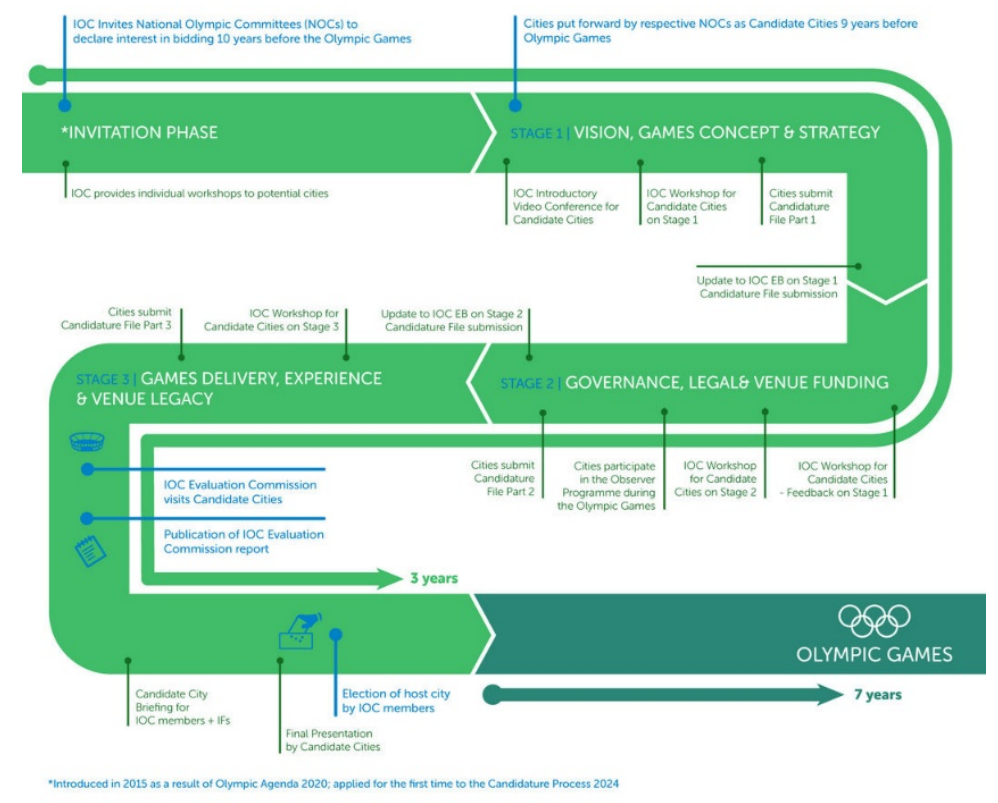

Figure 1 - involvement of stakeholders in Olympic games

(Source: www.olympic.org)

\subsection{What is Collaboration?}

Collaboration is a working practice in which individuals and organisations work together to achieve a common purpose. In the context of contracting, collaboration occurs when two or more participants work together to achieve a common business outcome while recognizing that each party may have different business objectives.

Collaboration in the procurement efforts of a project can range from good 'commonly used' practices within the traditional procurement model through to specific collaborative procurement models. Collaboration is seen as a normal activity in achieving project outcomes by mature client and 
contractor/supplier organisations and can mitigate potential conflicts; facilitate knowledge; and help to integrate the parties' specific capabilities to complete the project successfully (Rahmani et al., 2016).

The early contractor involvement (ECI) model of procurement is a collaborative contract approach to developing the tender for a project. Turner and Riding (2015) state that ECI broadly refers to the engagement that occurs between the project owner, designer and solution proponent (contractor/supplier) during the early stages of a project. The development of ECI was based on the premise that traditional methods create the team much too late in the project development and there is little scope for innovation and consideration of constructability (Edwards, 2009). Involving suppliers early in the project is seen to be an effective way of influencing project success (Aapaoja et al., 2013).

\subsection{Defining ECI}

Mosey (2009) describes ECI being developed by the Highways Authority in the United Kingdom (UK) during the early 1990s. The move to ECI was driven by the need to develop longer-term relationships with suppliers and create integrated project delivery teams (Whitehead, 2009). Since its initial use in the United Kingdom ECI has been adopted by government and public companies around the globe and is typically used in construction, defence, infrastructure, and transport infrastructure projects (Rahmani et al., 2013, Turner and Riding, 2015).

Within the literature, ECI does not have a single unified definition, it is defined in many different ways by different authors, the essence of the definitions is the same. For example: Nichols (2007) describes ECI as: "ECI is a form of partnering with the contractor appointed earlier than usual to help in planning, advise on 'buildability', and jointly develop a Target Price as the basis for a pain/gain share formula in the contract".

It is argued that as the traditional procurement model excludes the main contractor/supplier and subcontractors from the early design and project planning it inhibits opportunities for innovative solutions, constructability, and health and safety planning into design (Edwards, 2009, Mosey, 2009). On the other hand, ECI integrates people, systems, business structures, and practices into a process that collaboratively harnesses the talents and insights of all parties to optimize project results, increase value to the owner, reduce waste, and maximize efficiency through all phases of the project.

\subsection{Exploring the benefits and challenges of ECI}

The analysis of ECI construction and infrastructure projects by Whitehead (2009) identified many advantages over the traditional project delivery contracting models. This was supported by Rahman and Alhassan (2012a) who listed additional benefits of ECI.

In the United Kingdom, where ECI has been used since 2001, the generally held view is that there have not been any peculiar disadvantages identified with the model (Whitehead, 2009).

The analysis conducted by Rahman and Alhassan (2012a) identifies that involved parties' commitment and attitude to the performance of the ECI are two of the most important factors to achieve a successful outcome. All parties to an ECI must be willing and committed to building a lasting relationship (Mohr and Spekman, 1994) as the consequence of a party being unwilling to commit or the commitment being one-sided is that the trust relationship will be eroded (Kadefors, 2004). The parties will be unable to develop a win-win approach to the ECI if any of the parties is uncompromising in their attitude to the other the parties (Ng et al., 2002). A fear of change from the traditional ways, a lack of experience in working in ECIs, and past bad experiences from previous adversarial contracts can lead parties to be untrusting of one another (Glagola and Sheedy, 2002, Kadefors, 2004) 


\subsection{Common problems in event management}

An investigation of academic and industry publications into the problems associated with the planning and management of large or mega events unsurprisingly resulted in a similar list of project problems as those typically listed in construction, infrastructure, and ICT (Flyvbjerg, 2005, Flyvbjerg, 2011, Giezen, 2012, Müller, 2015a, Solberg and Preuss, 2015).

\subsection{Understudied areas and application of ECI}

Since ECI has been originally formulated for infrastructure and large-scaled construction projects, the majority of studies essentially focus on the different aspects of ECI within the building and construction industry (c.f. Song et al., 2009, Wondimu et al., 2016, Rahman and Alhassan, 2012b). However, a number of researchers also recognised the potential benefits of early involvement of contractor/supplier in other industries and conducted a few studies in different areas. For example, Wynstra et al. (2000) adopted the concept of ECI and developed the driving and enabling factors for purchasing involvement in product development within the business and marketing industry. Gil (2001) also utilized the principles of ECI in lean product-process development process to support contractor involvement during design.

Nevertheless, Turner and Riding (2015) observed in their review of key early contractor themes that an understudied area of ECI is the other involved parties such as: project managers, operations, maintenance, engineering, and asset management services. Another understudied area is the application of ECI in other industry segments such as event planning and management which is the focus of this study.

\section{Research Aim and Method}

This study sought to identify whether ECI is being applied to the procurement processes within the event planning and management industry and aimed to explore the potential benefits and challenges of the application of ECI within the event planning and management industry. This study was qualitative in nature taking an interpretivist philosophical position and employing a literature review approach.

The study gathered secondary data that was obtained from relevant academic and industry literature. The searches resulted in many articles involving ECI's use in the construction industry but few results involving ECI being used in the event planning and management industry, as a result the construction industry material was used as a basis for interpreting ECI in the event planning and management industry.

The motivation for this study was to investigate whether ECI would be a suitable contract vehicle to help overcome some of the common problems that plague the planning and delivery of large events. The scarcity of both academic and industry research that has been carried out and reported in journals and other publications on the use of ECI within the event planning and management industry has placed a constraint on this research study

\section{Analysis and Discussion}

Large and mega-events have a positive influence in local economies and tourist numbers (Teigland, 1999, Matheson, 2006) resulting in the ever increasing size and extravagance of these events and the continued expansion of the event planning and management industry. 
Current event planning and management industry guidelines suggest that large and mega-event projects require at least a two-year planning timeframe. This results in large and mega-events having extended planning and implementation stages. Flyvbjerg et al. (2004) have demonstrated that large and mega projects are subject to delays and cost overruns due to their extended planning and implementation stages.

To accommodate the growth in the size and frequency of these events the guidelines governing event planning and management require revising. Locatelli and Mancini (2014, p 285) suggested "new tools and guidelines are required to deliver events". One of the emerging tools is ECI. The ECI approach to procurement contracts is gaining popularity in the construction and infrastructure industries but there is little evidence to suggests it is a commonly used practice within the event planning and management industry.

In the late 1990s the UK's Highway Authority developed ECI. Around the same period Bramwell (1997) was advocating that event managers needed to engage in participatory planning processes and emphasized the importance of strategic planning for large and mega-events. Participatory planning is a euphemism for collaborative planning which is the premise for ECI.

The World Student Games held in Sheffield (UK) in 1991 suffered from greatly reduced visitor numbers, cost overruns, and other problems. The games used a traditional procedural procurement process and as Bramwell (1997, p 174) noted "...the games were sometimes depicted as crisis ridden...". A participatory planning process may have averted many of the problems by involving the contractor/suppliers early in the planning of the games. According to Peter Lundhus quoted by Bundgaard et al. (2011) "Too little use is made early on of the knowledge of contractors".

Although many authors have expressed the benefits of engaging with suppliers earlier in the project lifecycle, the event planning and management lifecycle (Figure 2 below) as defined by Event Management Book of Knowledge (EMBOK, 2016) suggests engaging with suppliers during the implementation phase of the event lifecycle, well after the event planning has taken place, therefore losing the opportunity to leverage the knowledge and expertise of the contractor/suppliers.

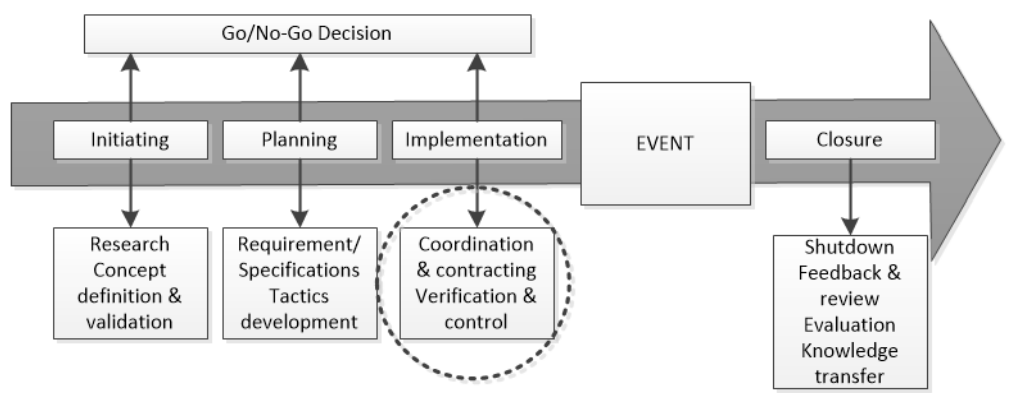

Figure 2 -Event planning and management lifecycle

(Source: EMBOK (2016))

At the moment, an "over-the-wall" practice prevails in the event planning and management industry where the event design is passed along the chain of parties until it is considered to be ready. This prevailing practice indicates an absence of a collaborative or participatory process to utilise the knowledge and experience of the contractors/suppliers during the planning stage. This prevailing practice leads to the overall event being sub-optimized as the individual stakeholders strive to optimize their own performance.

While the benefits of collaboration have been widely acknowledged by the construction industry, a successful partnering should begin early, prior to contract award or the procurement selection process in order to deliver the best value to a project (Rahmani et al., 2013). One of the more frequently 
observed benefits of ECI arises from the joint or participatory problem solving processes that is introduced early into the project resulting in "state-of-the-art knowledge being available from the contractor early on" (Bundgaard et al., 2011, p 28). This creates a better awareness and understanding of the risk profiles associated with the project. The longer term commercial consequences of a project will be better understood earlier in the lifecycle enabling appropriate remedies to be found earlier. This approach places the project owner in a position to identify and manage risks more effectively (Rahman and Kumaraswamy, 2004, Mosey, 2009).

Aapaoja et al. (2013) and many other authors have observed that the early involvement of contractors/suppliers in the project leads more efficient and effective problem solving and decision making. Swainston (2006) demonstrated that the cost of making a change early in a project is comparative low when compared to making that change later in the project's lifecycle.

Nevertheless, there are some barriers in involving a contractor at the early stage of a project, including challenges in the areas of contracting practice, teamwork and culture change (Song et al., 2009). One of the challenges is the contractors' concern about adequate regulations to prevent other competitors running off with their ideas and the intellectual property issues of their contributions to the design. Choosing suitable project participants for an ECI, and ambiguity in defining the role of consultants and their relationship between client and contractor throughout an ECI contract also can be seen as the challenges in using an ECI (Bundgaard et al., 2011). Clients also find competition and trust as challenges they might face in adapting an ECI contracting model (Bundgaard et al., 2011). Scheepbouwer and Humphries (2011) examine ECI against the transitional projects issues and assert that disagreement over risk allocation, time constraints and cost reimbursement as well as level of staff capability and input, are issues in implementing ECI project delivery for all committed parties that should be adequately addressed.

\section{Concluding Remarks}

This study was based on an exploration of existing literature. The event planning and management industry appear to be locked into the traditional procurement cycle and scant evidence was uncovered in the academic and industry literature to demonstrate that ECI is being applied in any meaningful way. The exploration of the literature has demonstrated that the problems experienced in large and megaevent projects are essentially the same problems that were experienced in the construction and infrastructure project prior to the adoption of ECI.

Many authors have written on the benefits and drawbacks of ECI in the construction and infrastructure industries. ECI is essentially a simple change to the "when" the contractor/suppliers are engaged in the procurement activities of a project so that their knowledge and expertise can be leveraged.

This change to the "when" the contractors/suppliers are engaged can be applied to all projects regardless of the industry domain. ECI could be applied to the event planning and management industry and the industry could expect to receive many of the same benefits that have been observed in the construction and infrastructure industries.

While the findings of this study are limited, they provide a basis from which further research can occur in understanding the benefits and drawbacks of ECI in the event planning and management industry. Further research to gather primary data will allow for a deeper analysis of the interaction of ECI in the management of large and mega-events and the opportunity to compare the outcomes with construction and infrastructure projects. 


\section{References}

AAPAOJA, A., HAAPASALO, H. \& SÖDERSTRÖM, P. 2013. Early stakeholder involvement in the project definition phase: case renovation. ISRN Industrial Engineering, 2013.

BRAMWELL, B. 1997. Strategic planning before and after a mega-event. Tourism Management, $18,167-176$.

BUNDGAARD, K., KLAZINGA, D. \& VISSER, M. 2011. Traditional procurement methods are broken: can early contractor involvement be the cure?'. Terra et Aqua, 124, 25-30.

EDWARDS, R. 2009. Early contractor involvement (ECI) contracts in the south Australian transport infrastructure construction industry. Adelaide, Australia: Department for Transport Energy and Infrastructure (DTEI).

EMBOK. 2016. Event Management Body of Knowledge [Online]. http://www.embok.org/index.php: EMBOK.ORG. [Accessed 24 May 2016].

FLYVBJERG, B. 2005. Design by deception: The politics of megaproject approval.

FLYVBJERG, B. 2011. Over budget, over time, over and over again: Managing major projects. Over and Over Again: Managing Major Projects.

FLYVBJERG, B., SKAMRIS HOLM, M. K. \& BUHL, S. L. 2004. What causes cost overrun in transport infrastructure projects? Transport reviews, 24, 3-18.

GIEZEN, M. 2012. Keeping it simple? A case study into the advantages and disadvantages of reducing complexity in mega project planning. International Journal of Project Management, 30, 781790 .

GIL, N. 2001. Product-process development simulation to support specialty contractor involvement in early design. Ph. D. Diss., Civil \& Envir. Engrg., Univ. of California, Berkeley.

GLAGOLA, C. R. \& SHEEDY, W. M. 2002. Partnering on defense contracts. Journal of Construction Engineering and Management, 128, 127-138.

KADEFORS, A. 2004. Trust in project relationships-inside the black box. International Journal of project management, 22, 175-182.

LOCATELLI, G. \& MANCINI, M. 2014. Controlling the delivering of projects in mega-events: An application on EXPO 2015. Event Management, 18, 285-301.

MATHESON, V. 2006. Mega-Events: The effect of the world's biggest sporting events on local, regional, and national economies.

MOHR, J. \& SPEKMAN, R. 1994. Characteristics of partnership success: partnership attributes, communication behavior, and conflict resolution techniques. Strategic management journal, 15, 135 152.

MOSEY, D. 2009. Early contractor involvement in building procurement: contracts, partnering and project management, John Wiley \& Sons.

MÜLLER, M. 2015a. The mega-event syndrome: Why so much goes wrong in mega-event planning and what to do about it. Journal of the American Planning Association, 81, 6-17.

MÜLLER, M. 2015b. What makes an event a mega-event? Definitions and sizes. Leisure Studies, 34, 627-642.

NG, S. T., ROSE, T. M., MAK, M. \& CHEN, S. E. 2002. Problematic issues associated with project partnering - the contractor perspective. International Journal of Project Management, 20, 437-449.

NICHOLS, M. 2007. Review of Highways Agency's Major Roads Programme, Report to Secretary of State for Transport. The Nichols Group.

PMI 2013. A Guide to the Project Management Body of Knowledge 5th edition, Project Management Institute, Incorporated.

RAHMAN, M. \& ALHASSAN, A. 2012a. A contractor's perception on early contractor involvement. Built Environment Project and Asset Management, 2, 217-233.

RAHMAN, M. M. \& ALHASSAN, A. 2012b. A contractor's perception on Early Contractor Involvement. Built Environment Project and Asset Management, 2, 1-1. 
RAHMAN, M. M. \& KUMARASWAMY, M. M. 2004. Contracting relationship trends and transitions. Journal of Management in Engineering, 20, 147-161.

RAHMANI, F., KHALFAN, M. \& MAQSOOD, T. The use of early contractor involvement in different countries. AUBEA 2013, 2013. University of Auckland, 1-10.

RAHMANI, F., KHALFAN, M. M. \& MAQSOOD, T. 2016. Analysing the drivers for early contractor involvement adoption by construction clients. International Journal of Procurement Management, 9, 373-397.

SCHEEPBOUWER, E. \& HUMPHRIES, A. 2011. Transition in adopting project delivery method with early contractor involvement. Transportation Research Record: Journal of the Transportation Research Board, 44-50.

SILVERS, J. R. 2009. Risk management for meetings and events, Routledge.

SOLBERG, H. A. \& PREUSS, H. 2015. Major Sports Events: The Challenge of Budgeting for the Venues. Event Management, 19, 349-363.

SONG, L., MOHAMED, Y. \& ABOURIZK, S. M. 2009. Early contractor involvement in design and its impact on construction schedule performance. Journal of Management in Engineering, 25, 1220.

SWAINSTON, M. 2006. Early contractor involvement. Queensland Roads.

TEIGLAND, J. 1999. Mega-events and impacts on tourism; the predictions and realities of the Lillehammer Olympics. Impact assessment and project appraisal, 17, 305-317.

TURNER, N. \& RIDING, M. 2015. Early contractor involvement in Australia: Learnings from Transfield Services projects. Small Enterprise Research, 22, 173-184.

WHITEHEAD, J. 2009. Early Contractor Involvement-The Australian Experience. Const. L. Int'l, $4,20$.

WONDIMU, P. A., HAILEMICHAEL, E., HOSSEINI, A., LOHNE, J., TORP, O. \& LÆDRE, O. 2016. Success Factors for Early Contractor Involvement (ECI) in Public Infrastructure Projects. Energy Procedia, 96, 845-854.

WYNSTRA, F., AXELSSON, B. \& WEELE, A. 2000. Driving and enabling factors for purchasing involvement in product development. European Journal of Purchasing \& Supply Management, 6, 129141. 